\title{
Six Years of Freshman Retention Efforts: Where are We Now?
}

\section{Prof. Alan D. Niemi, LeTourneau University}

Alan D. Niemi is a Professor of Electrical Engineering Technology at LeTourneau University. He received his B.S. in Electrical Engineering Technology from Lake Superior State University and his M.S.E.E. from Illinois Institute of Technology. He has taught courses in Electrical Engineering and Technology for 30 years. In addition to teaching, Professor Niemi has spent 7 years in industry designing digital and microcontroller systems.

\section{Mr. Jeff Johnson, LeTourneau University}

Jeff Johnson is an Assistant Professor at LeTourneau University. He received his B.S. in Mechanical Engineering Technology from LeTourneau in 1994 then proceeded to spend 16 years in industry focusing on machine and civil design as well as project management. In 2010 he began his teaching career at his alma mater to share his experiences with engineering and technology students. He earned a masters in Engineering Project Management from Eastern Michigan University in 2014. He is currently a co-PI on the schools NSF-STEP retention grant. 


\title{
Six Years of Freshman Retention Efforts: Where are We Now?
}

\begin{abstract}
The First-Year Initiatives for Retention Enhancement (FIRE) project has sought to increase engineering graduation rates from a five-year average of $42 \%$, to $65 \%$ by increasing the $1^{\text {st }}$ to $2^{\text {nd }}$ year retention from $68 \%$ to $85 \%$. Each year the FIRE efforts have included all of the roughly 140 "First time in college" (FTIC) students in LeTourneau University's School of Engineering and Engineering Technology (SEET) programs. An internal study and best-practices literature review prompted several initiatives beginning in 2010:

1) implementing peer, faculty, and industrial mentoring for first-year students;

2) implementing an engineering "freshman experience" class;

3) implementing first-year engineering practice classes including professional topics and openended experimentation and design projects.
\end{abstract}

First-year Interest Groups (FIGs) of 8-10 similar-major students have been paired with peer mentors, faculty mentors, and in some cases, industrial mentors. These groups have synergized with existing university support structures, and have been the catalysts for several aspects of our program being adopted university-wide. Surveys over the years have indicated that both mentors and the students are largely positive about FIG group mentoring.

We built upon existing infrastructure to create an engineering flavor of the university's "freshman experience" course in which engineering faculty mentored FIG groups in a curriculum including time management and study skills. Over the years, this format has evolved from 25-30 students in a section, to the current format of 10 students in a section taught by their faculty mentor. This more personal setting, focusing on aspects of "how to thrive in college" has produced much improved student course evaluations.

First-year students have participated in two engineering practice courses which are designed to answer the question "what do engineers do?" The first course includes interactive classroom sessions on engineering practice and experiential lab modules exposing students to various fields of engineering. The second course includes engineering design with robotics and microcontroller platforms. A Freshman Engineering Pre/Post Survey has indicated the students' scores improve sizably related to their awareness of, and commitment to, the engineering profession.

In addition to the positive results above indicating progress on grant sub-goals, one-year retention has increased by an average of nearly $8 \%$ after six years of the project. Also, the sixyear graduation rate has increased by over $13 \%$.

This executive summary, and associated poster, will provide more details of the retention initiatives employed, and will present qualitative and quantitative assessment results of the project, with the intention of contributing our experiences and findings to the continuing dialogue on retention initiatives. This project has been supported by an NSF-STEP grant. 


\section{Executive Summary}

Initiatives. The project initiatives include extensive mentoring through first year interest groups, developing college life skills in a freshman experience class, and exposing students to engineering practice through two new freshman courses that incorporate active-learning projects.

1) Peer, Faculty, and Industrial Mentoring for first-year students. First-year Interest Groups (FIGs) of 8-10 similar-major students meet weekly with peer mentors in both group and individual meetings. These meetings range from study sessions, to social events such as sports attendance, movies, meals, and games. The FIGs also meet with their faculty mentors weekly for the first 10 weeks of the semester during their freshman experience class (described below) and additionally for dessert, meals, and recreational activities. Some FIGs additionally meet with industrial mentors during classroom presentations or plant trips - although this aspect of mentoring is no longer a requirement of retention program. The student peer mentors meet every two weeks with the project co-PI and with the faculty mentor of their FIG group. These groups synergize with existing support structures in the university's student services area, and were the catalyst for several aspects of our retention program being adopted university-wide.

First-year students completed multiple surveys as did peer and faculty mentors. Results from both mentors and the students are relatively positive about FIG group mentoring, and included some formative guidance. When asked (Fall 2016) if mentoring had been a positive experience, $100 \%$ of peer mentors, $100 \%$ of faculty mentors said they strongly agreed or agreed. While the first-year students themselves were not quite as positive, $90 \%$ strongly agreed or agreed that their peer mentor was a source of positive support to them their first semester and $85 \%$ indicated that their faculty mentor (academic advisor) has been influential in their success at LeTourneau University. Although freshman survey comments were few, many of those provide are reflected in, "I was very satisfied with my experience".

2) Engineering "Freshman Experience" Class. We have built upon existing infrastructure to create an engineering flavor of the university's "freshman experience" course in which engineering faculty mentor their FIG groups ( 10 students) in a curriculum including goal setting, time management, study skills, and relational, professional, and character development as set-forth in Thriving at College by Alex Chediak. The weekly assigned book readings and associated study questions are the focus of the 10-week, one credit hour course.

Over the last three years, this format has evolved from 25-30 students in a section, to the current format of 10 students in a section taught by their faculty mentor. This more personal setting, focusing on aspects of "how to thrive in college" has produced much improved student course evaluations and has increased faculty satisfaction.

In the fall of 2016, the fourteen engineering faculty leading each section received overall high student evaluations (weighed average 4.4 of 5.0), however, the course content itself was not unanimously favorably evaluated by students. Some students felt that they already knew how to manage themselves well, while others echoed the course evaluation comment, "I came into this course believing it would be a waste of time. I would say I was very wrong. This course helped me put my new life situation in perspective and gave me some great pointers on what to do with my time here." When asked (Fall 2016) if the FIG has helped students develop successful life 
skills and study habits (both taught in the freshman experience class), $90 \%$ of peer mentors, and $100 \%$ of faculty mentors said they strongly agreed or agreed.

3) First-year Engineering Practice Classes. First-year students participate in two engineering practice courses which are designed to answer the question "what do engineers do?" The first course includes interactive classroom sessions on both qualitative and quantitative aspects of engineering practice and an intentional exposure to the various fields of engineering. A handson lab module parallels the course in which every freshman student builds their own 3-D printer during the semester. (In the spring of 2014, engineering students in this class set the Guinness World Record for the greatest number of 3-D printers running simultaneously!) The second course includes engineering design with platforms of LEGO robotics and Arduino microcontrollers.

A Freshman Engineering Pre/Post Survey was designed to assess majors' awareness of their discipline prior to completion of discipline-specific coursework. Responses to this survey were scored from $1=$ Strongly Disagree to $5=$ Strongly Agree and it was administered at both the beginning and the end of the first semester as part of the engineering practice course. Simple descriptive statistics indicated which items improved in the second administration, and vice versa. Additional analyses identified the level of effectiveness of each survey item using paired samples $t$-tests and Cohen's $d$, as well as the level of effect according to Cohen (1992t) for items that were statistically significant $(\mathrm{p}<0.05)$, and which had a noteworthy effect size $(|\mathrm{d}|>0.2)$. Particularly satisfying (Fall 2015) was the increase in the students' understanding of the engineering profession $(\mathrm{p}<0.01,|\mathrm{~d}|=0.4)$ which is one of the three desired short-term project outcomes. This and other items indicated that the course is positively impacting freshmen in their awareness of, and commitment to, the engineering profession.

The course evaluations given at the end of the semester in the two new Introduction to Engineering Practice courses reveal:

- $\quad$ F15, ENGR1513 - overall course rating $=4.4$ of 5.0, indicating $88 \%$ satisfaction

- S16, ENGR1523 - overall course rating $=4.0$ of 5.0, indicating $80 \%$ satisfaction

According to the surveys and course evaluation results, first-year course initiatives of the project are providing meaningful and satisfactory experiences for the first-year students.

Results. Retention rates are shown in Figure 1 for entering cohorts. After the first 6 years of the project the 2015 cohort one-year retention rate was $85 \%$ for "first time in college" (FTIC) students in the School of Engineering \& Engineering Technology. This rate meets the project target of $85 \%$ for the 2015 cohort, and is the highest ever achieved by the school. 


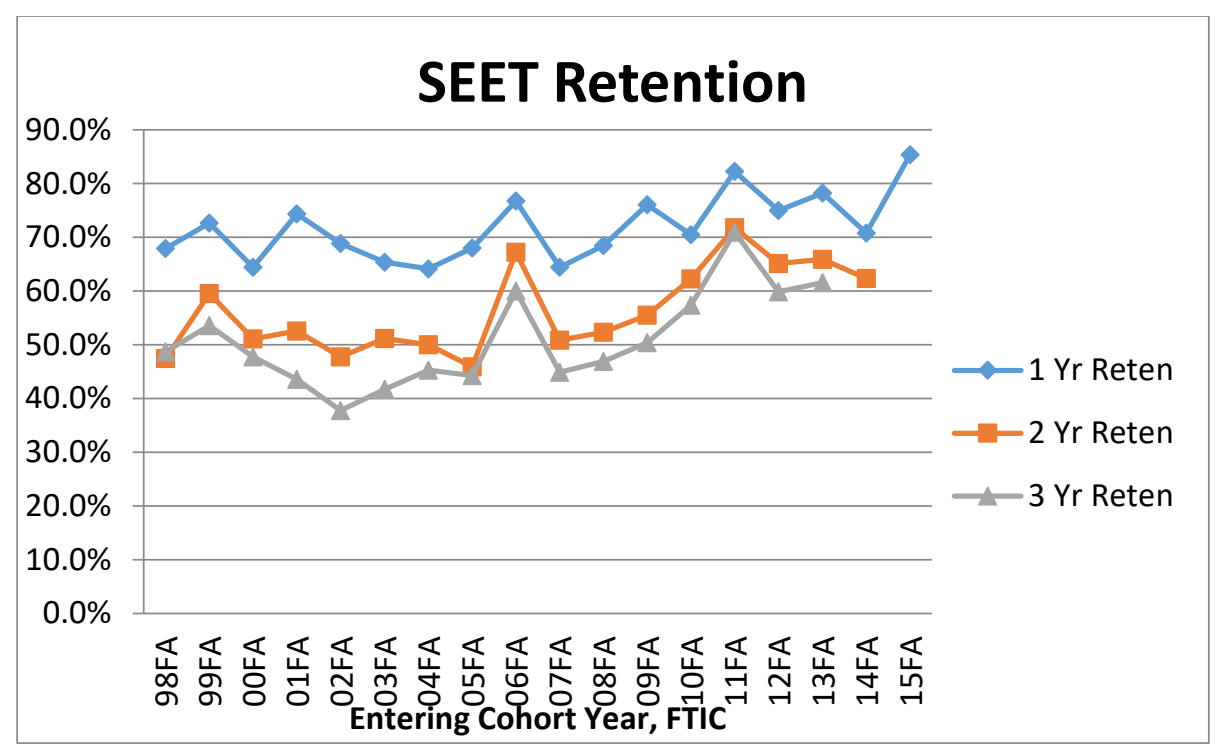

Figure 1. Retention in Engineering and Engineering Technology

Admittedly, since all of the incoming FTIC students in the SEET experience the internal influences of the FIRE project initiatives (no control group), it is not possible to separate the effects that FIRE is having on the current population. It is reasonable however, to compare retention during the grant period with that of the prior years, realizing that there are some internal and external factors that were not held constant, such as curriculum, professors, economic conditions, etc. As seen in Figure 2, the current trend indicates an average increase in retention of $\mathbf{7 . 6 \%}$ over the historic SEET baseline suggesting positive project impact.

Comparing the retention of SEET students during the grant period with that of the rest of the university during the same period minimizes the effects that external influences have on the analysis since both groups are experiencing similar life conditions. As shown in Figure 2, the average 1-year retention for the SEET cohorts experiencing the full complement of project initiatives (since 2011) is significantly higher than the rest of the university. This data again suggests that the project is having a significant positive impact on retention.

\begin{tabular}{|c|c|c|}
\hline Cohorts & $\begin{array}{c}\text { SEET } \\
\text { Starters }\end{array}$ & All Others \\
\hline $05,06,07,08,09$ & $70.8 \%$ & $70.6 \%$ \\
$11,12,13,14,15$ & $78.3 \%$ & $70.9 \%$ \\
& & \\
\hline Change & $7.6 \%$ & $0.3 \%$ \\
\hline
\end{tabular}

Figure 2. Average One-Year Retention Comparison 
Challenges. As the academic year progresses our busy first-year students identify with multiple groups other than "First-year Interest Groups" and peer mentors become increasingly busy and burned out. Therefore, we have chosen to frontload the mentoring interactions to the fall semester and back-off on the number of required meeting in the spring. While recruiting faculty mentors has always been a challenge, it has actually become easier in the last two years as they are seeing the effectiveness of the program, and are more willing to host the smaller group size. Our industrial mentoring component is now an optional part of the retention program, due to the difficulty of obtaining mentors for all fourteen FIGs. This decision was also influenced by the lower value given to the industrial mentor experiences indicated by our freshman surveys. We are continually streamlining and strategizing to maximize efficiency to prepare for sustainability as our grant funding comes to an end.

\section{Acknowledgements}

Prior versions of some of the information provided in this executive summary has been presented in various forms in previous ASEE papers ${ }^{1,2,3,4,5}$ that address other aspects of this project. The data provided here has been updated to reflect the state of the project at the time of this writing.

This project, entitled First-Year Initiatives for Retention Enhancement, is supported by the National Science Foundation under Grant No. 0969382. Any opinions, findings, and conclusions or recommendations expressed in this material are those of the authors and do not necessarily reflect the views of the National Science Foundation.

\footnotetext{
1. Niemi, A., and Warke, R., "Facing Our Retention Problem: A Self-Portrait", Proceedings of the 2011 American Society for Engineering Education Conference\& Exposition, Annual Conference, 2011.

2. Green, M., Niemi, A., and Roudkovski, M., "Implementing an Industrial Mentoring Program to Enhance Student Motivation and Retention", Proceedings of the 2012 American Society for Engineering Education Conference \& Exposition, Annual Conference, 2012.

3. Niemi, A., Green, M., and Roudkovski, M, "Evaluation of a First-Year Retention Project: Findings at Halftime", Proceedings of the 2013 American Society for Engineering Education Conference \& Exposition, Annual Conference, 2013.

4. Johnson, J., Niemi, A., "Management and Assessment of a Successful Peer Mentor Program for In-creasing Freshmen Retention", Proceedings of the 2014 American Society for Engineering Education Conference\& Exposition, Annual Conference, 2014.

${ }^{5}$ Johnson, J., Niemi, A., “A First-year Attrition Survey: Why Do They Say They Are Still Leaving?”, Proceedings of the 2015 American Society for Engineering Education Conference \& Exposition, Annual Conference, 2015.
} 